\title{
A steady-state method for computation of myocardial blood volume with the intravascular contrast agent Ablavar
}

\author{
Octavia Biris ${ }^{1,2^{*}}$, Brandon Benefield ${ }^{3}$, Kathleen R Harris ${ }^{3}$, Daniel C Lee $^{3,4}$ \\ From 15th Annual SCMR Scientific Sessions \\ Orlando, FL, USA. 2-5 February 2012
}

\section{Summary}

Our proof of principle results show the feasibility of quantifying myocardial blood volume (MBV) with the intravascular contrast agent MS-325. For severe stenoses in a canine model, stenosis zone MBV was higher than remote $\mathrm{MBV}$ at rest, and lower than remote during vasodilation.

\section{Background}

In contrast echocardiography, absolute MBV in $\mathrm{ml} / 100$ $\mathrm{g}$ tissue has been shown to correlate with myocardial flow reserve at stress. Furthermore, MBV increases with severity of stenosis at rest, raising the possibility of detecting CAD without a stressor. We show proof of principle that MBV can be quantified by CMR using the intravascular contrast agent MS-325.

\section{Methods}

Protocol: We performed two rest-stress imaging experiments in an instrumented dog with a left circumflex coronary (LCX) artery stenosis created by hydraulic occluder. Severity of stenosis was evaluated by reduction in myocardial blood flow (MBF) measured by microspheres. During both experiments, the animal received $0.006 \mathrm{mmol} / \mathrm{kg}$ MS-325 (Ablavar) at rest and again during adenosine stress. T1 mapping was performed before and after contrast administration on a $1.5 \mathrm{~T}$ Espree (Siemens, Erlangen, Germany), with the MOLLI pulse sequence (short axis slice $8 \mathrm{~mm}$, FOV 171 x $343 \mathrm{~mm} 2$, TR $173 \mathrm{~ms}$, effective TI $100 \mathrm{~ms}$ ), before and after administration of contrast agent.

${ }^{1}$ Radiology, Northwestern University, Chicago, IL, USA

Full list of author information is available at the end of the article

\section{Image Processing}

We have estimated the $\mathrm{T} 1$ changes in the myocardium and left ventricle blood pool through fitting of MOLLI signal to the Look-Locker regrowth curve $(\operatorname{Signal}(\mathrm{t})=\mathrm{M} 0$ (1-inf(exp(-t/T1*)) in MATLAB R2009a. MBV was calculated by signal difference maps, according to a slow water exchange model. The final quantitative MBV values were obtained after hematocrit, density and water exchange correction $\left(\mathrm{MBV}(\mathrm{ml} / 100 \mathrm{~g})=100^{*}(1 / \mathrm{WCF})^{*}\right.$ $0.95 *$ (1-HCTventricle)/(1-HCTcapillary)* MBV (\%), with a ventricular hematocrit of 0.4 , and capillary hematocrit 0.2). We assumed slow water exchange with a correction factor (WCF) of 4, based on previous experiments.

\section{Results}

Measurements of MBV and MBF over the whole myocardium, in the stenosis zone, and in a healthy remote zone are summarized in Table 1 . The stenoses caused flow reduction at rest (36\% and $25 \%$ reduction in $\mathrm{MBF}$ ), associated with an increase in MBV in the stenosis zone compared to the remote zone (33\% and 9.9\%). At stress, average MBV increases, but stenosis zone MBV is lower than remote MBV (20.1\% and 19.9\%). For both experiments, MBV and MBF reserves (MVR and MFR) are in the range of published values.

\section{Conclusions}

MBV can be quantified by CMR using the intravascular agent MS-325. Our MBV results mirror the expected vasodilation of microvessels distal to a resting epicardial stenosis, which results in a rest increase of MBV. Under maximal pharmacologic vasodilation, the limitation in epicardial flow results in lower MBV in the stenosis zone relative to the remote zone. 
Table 1 MBV by MRI shows expected relationship to MBF by microspheres

\begin{tabular}{|c|c|c|c|c|c|}
\hline \multicolumn{6}{|c|}{ Experiment 1} \\
\hline & Rest & & Stress & & \\
\hline & MBV (ml/100g) & \% MBV increase (Stenosis-Remote)/Remote & MBV $(\mathrm{ml} / 100 \mathrm{~g})$ & \% MBV reduction (Stenosis-Remote)/Remote & MVR \\
\hline Average & 4.923 & & 5.771 & & 1.172 \\
\hline Stenosis & 6.186 & 33.0 & 5.395 & 20.07 & 0.872 \\
\hline Remote & 4.651 & & 6.75 & & 1.451 \\
\hline \multicolumn{6}{|c|}{ Flow from microspheres } \\
\hline & Rest & & Stress & & \\
\hline & $\mathrm{MBF}(\mathrm{ml} / \mathrm{min} / \mathrm{g})$ & $\%$ Flow reduction (Stenosis-Remote)/Remote & $\mathrm{MBF}(\mathrm{ml} / \mathrm{min} / \mathrm{g})$ & \%Flow reduction (Stenosis-Remote)/Remote & MFR \\
\hline Stenosis & 0.961 & 35.98 & 0.714 & 838.495 & 0.742 \\
\hline Remote & 1.502 & & 8.469 & & 5.638 \\
\hline \multicolumn{6}{|c|}{ Experiment 2} \\
\hline & Rest & & Stress & & \\
\hline & MBV (ml/100g) & $\% \mathrm{MBV}$ increase (Stenosis-Remote)/Remote & MBV (ml/100g) & \%MBV reduction (Stenosis-Remote)/Remote & MVR \\
\hline Average & 3.241 & & 4.828 & & 1.490 \\
\hline Stenosis & 3.669 & 9.85 & 4.335 & 19.94 & 1.182 \\
\hline Remote & 3.340 & & 5.415 & & 1.833 \\
\hline \multicolumn{6}{|c|}{ Flow from microspheres } \\
\hline & Rest & & Stress & & \\
\hline & $\mathrm{MBF}(\mathrm{ml} / \mathrm{g} / \mathrm{min})$ & \%Flow reduction (Stenosis-Remote)/Remote & $\mathrm{MBF}(\mathrm{ml} / \mathrm{g} / \mathrm{min})$ & \% Flow reduction (Stenosis-Remote)/Remote & MFR \\
\hline Stenosis & 0.687 & 25.239 & 0.908 & 627.226 & 1.322 \\
\hline Remote & 0.918 & & 6.414 & & 8.583 \\
\hline
\end{tabular}

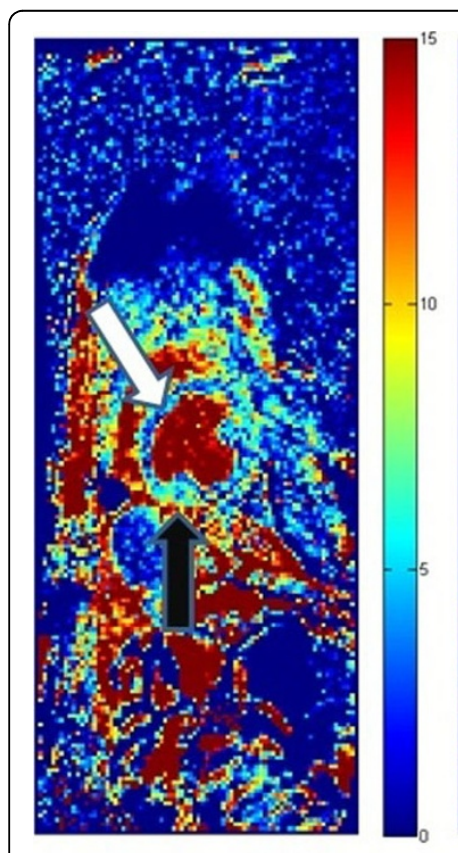

a1

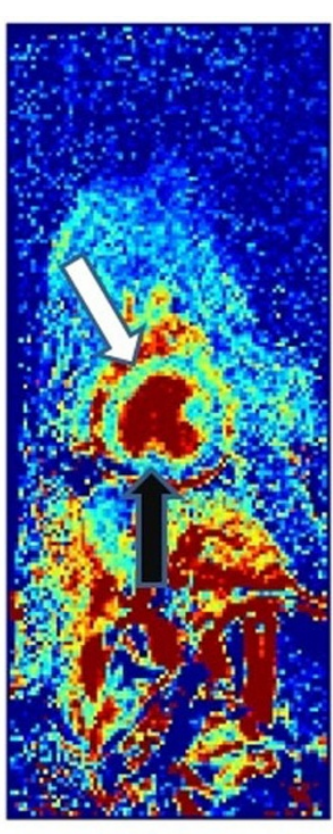

a2

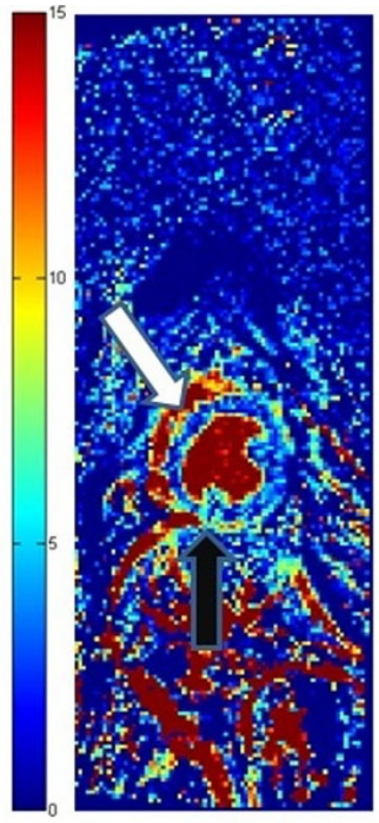

b1

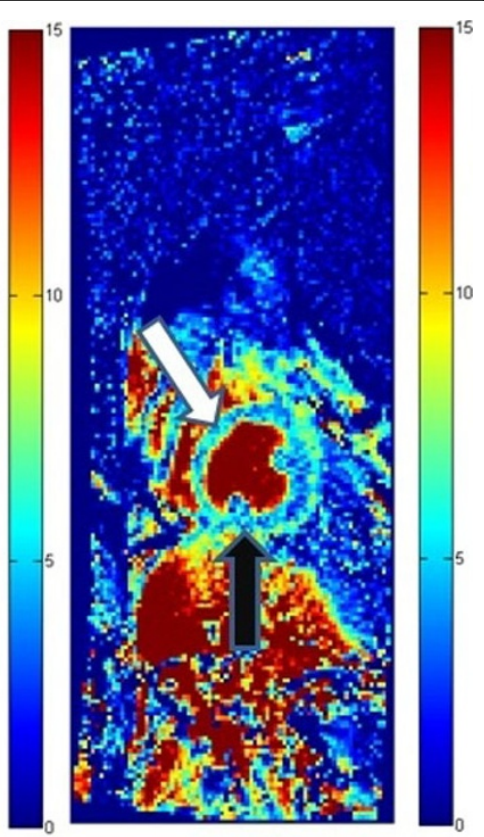

b2

Figure 1 Myocardial blood volume maps show feasibility of steady state MBV images with adenosine stress. Quantitative MBV (ml/100g tissue) maps in a canine with LCX stenosis: a1) Severe stenosis at rest causes vasodilation or MBV increase in the LCX bed or inferior myocardium (black arrow) compared to anteroseptal remote regions (white arrow) a2) At stress, inferior area experiences less MBV increase b1) Less severe stenosis shows less marked increase in inferior MBV at rest b2) At stress, inferior MBV increases less than MBV in remote area. 


\section{Funding}

None.

\section{Author details}

${ }^{1}$ Radiology, Northwestern University, Chicago, IL, USA. ${ }^{2}$ Biomedical

Engineering, Northwestern University, Evanston, IL, USA. ${ }^{3}$ Feinberg

Cardiovascular Institute, Northwestern University, Chicago, IL, USA. ${ }^{4}$ Feinberg

School of Medicine, Northwestern University, Chicago, IL, USA.

Published: 1 February 2012

doi:10.1186/1532-429X-14-S1-P49

Cite this article as: Biris et al:: A steady-state method for computation of myocardial blood volume with the intravascular contrast agent Ablavar. Journal of Cardiovascular Magnetic Resonance 2012 14(Suppl 1):P49.

Submit your next manuscript to BioMed Central and take full advantage of:

- Convenient online submission

- Thorough peer review

- No space constraints or color figure charges

- Immediate publication on acceptance

- Inclusion in PubMed, CAS, Scopus and Google Scholar

- Research which is freely available for redistribution

Submit your manuscript at www.biomedcentral.com/submit 